the following advantages: first, more speedy and certain action; secondly, the smaller amount necessary to be given, and consequently the less risk of injuriously affecting the constitution; thirdly, the great advantage of knowing that your remedy is taken, and has a fair chance of doing its duty.

I am glad to confirm, by experience, the suggestion made by $\theta \varepsilon \omega \rho o s$, of the probable efficacy of emetics; and I should observe, that the cases in which $I$ have found them most useful and generally employ them are those in which vomiting or nausea form a predominant symptom; or where there is great sense of oppression in the procordial or epigastric region; and in these cases the sedative effect of calomel is afterwards remarkably conspicuous.

My card is entirely at your service; but I would prefer gain to subscribe myself, Sir, yours very obediently,

August 25, 1849 .

A. B. M.

This correspondent appends the following

Summary of the Cases reported by Mr. Cox. Recoveries.

Reaction in Consumed.

3 most speedy, taking 5 grs. every $10 \mathrm{~min}$. .. $2 \mathrm{hrs}$. .. $60 \mathrm{grs}$.

$\mathbf{5}$ $3 \mathrm{grs}$. every $10 \mathrm{~min}$. . $3 \mathrm{3}$ hrs.. $.54 \mathrm{grs}$. $3 \mathrm{grs}$. every $15 \mathrm{~min}$.
taking $2 \mathrm{gits}$. every $10 \mathrm{~min}$.
Ditto ditto Ditto ditto Ditto ditto

10 hrs. 10 hrs. $\because 192$ grs.

$\therefore 19$ hrs. .. 144 grs.

6 hrs. $\ldots 72$ grs.

2 taking 1 gr. every 5 min., each 14 hrs. $\ldots 108 \mathrm{grs}$.

8 Time previous to rallying not stated.-Total, 18 .

$$
\begin{aligned}
& \text { Deaths. Died in Having taken }
\end{aligned}
$$

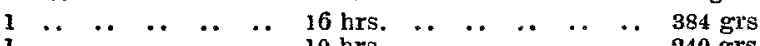

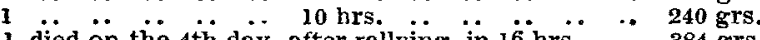

$$
\begin{aligned}
& 1 \text { died on the } 4 \text { th day, after rallying, in } 16 \text { hrs. .. } 384 \text { grs. } \\
& 1 \text { died on the 3rd day, after rallying, in } 20 \mathrm{hrs} \text {. .. } 480 \mathrm{grs} \text {. } \\
& 2 \text { Time previous to death not stated. }- \text { Total, } 6 \text {. }
\end{aligned}
$$

\section{ANALYSES OF COMMUNICATIONS ON THE} TREATMENT OF CHOLERA.

A CORRESPONDENT, signing himself " $R$." remarks, "Amongst numerous remedies for the treatment of cholera, I see no notice taken of one, which in India has been found of the utmost utility in checking an attack of the diseaseviz., quinine. It is there given along with calomel and opium, which two medicines have been for ever used in Indian practice, for the purpose of restraining the violent action of the intestines, and allaying emesis. This combination of medicines has been found to check the diarrhoea, and at the same time to rouse the depressed nervous system; and in the low form (?) of cholera which is at present raging in London, it would, I have no doubt, be found equally efficacious. It must, however, be given in the early stages of the disease, and in large doses."

The writer furnishes us with an extract from a report on cholera, by a gentleman of the greatest practical knowledge in the treatment of the disease.- "I cannot forbear recording my testimony to a combination of medicines, which, in warding off and checking an attack of cholera in numerous instances, both in Europeans and natives, has been followed with the happiest results. The remedy consists of quinine, calomel and opium, in the quantities of six, four, and two grains respectively, followed by a wineglass of brandy diluted with a little warm water. This given within the first hour or two of seizure, will be found, in a large proportion of cases, to check the disease."

"Hovo" says-" Amongst the many remedies for cholera, brandy is vaunted as useful and important.

"Have we hitherto learned that 'brandy' has relieved or cured? I think not. It is a ready and popular resource, which has been grasped or handled readily, in extremity, on the 'do something' principle.

"Suppose the malady were less active, how unwillingly should we administer a powerful stimulant where there is irritation of the inner surface of the stomach or intestines? The ratio is the same. Give brandy in cholera-you do harm. How often has diarrhoea been checked easily and safely after the assertion-' $\mathrm{Oh}$, Sir, I have taken some brandy, but I find my= self no better'?

"In the latter stages the patients suffer great debility; their powers are prostrated, from the vis medicatrix naturce and from doses of chalk-and-opium; they are partly exhausted and partly narcotised. As soon as the vomiting, purging, or pain, has ceased, let the patient remain quiet; do nothing for ten or twelve hours medically, but see that the extremities are kept warm; leave the patients alone, you cannot do them any good. After twelve hours has elapsed, maybe some reaction has taken place. Then comes nursing. Avaunt with your physic! Give some strong beef-tea, arrowroot, or gruel, at intervals, for the next twenty-four hours, then a couple of rhubarb pills at bed-time, and let the patient remain under the doctor's supervision for a week.

Another correspondent, signing himself "RoBERTus," remarks,-

"I am utterly at a loss to reconcile the various distinctions which the Board of Health and other reporters of the disease make between the premonitory symptoms and the disease itself. We have simple diarrhoea, rice-water purging, serous diarrhœa, bilious diarrhcea, cholerine, and cholera. With regard to the calomel treatment, I have made extensive inquiries, and with regard to the other plans of treatment, I have also made extensive inquiries, and, without exception, I have found in the modes of treatment of some dozen medical men (none of which were wholly similar,) that opium is an ingredient of them all. With regard to the hopeless cases, one person has assured me that he has given four grains of opium immediately, and a grain every hour afterwards; and another, that he has given calomel in immense doses at short intervals, both without any ill effects. The inference that I draw from this is, that in this unfortunate stage nothing can do either hurt or good, and that such cases are not fit ones for the elucidation of the treatment of this mysterious disease. In the practice with which I am connected, I have observed that stimulants and opium, with the application of external heat, cataplasms to the epigastrium, (in case of sickness,) and hot fomentations to the abdomen, have been followed with the most unequivocal and beneficial effects; but in those cases which have displayed a more than ordinary virulence, or in which the premonitory symptoms have been neglected till a state of profound collapse has supervened, these remedies have been wholly useless. Opium in all cases has been our sheet-anchor-in fact, the sine quâ non of successful treatment."

\section{A coRrespondent writes,-}

"May I beg, Mr. Editor, that you will suggest the propriety of all your correspondents who write about remedies in cholera, adopting the plan of recording the symptoms of their Asiatic cholera, and we may then know what conclusions to come to respecting the propriety of the treatment adopted, and its success. I beg you will allow me to thank Mr. W. J. Cox for his experience, and to remain,

Hitchin, August, 1849.

Sir, your very obedient servant, JaCOBUs AvaLYsis, M.D.

\section{ZRebíngs.}

Observations on Hospital Gangrene. By JoHn BoGgIE, M.D.s Surgeon to her Majesty's Forces. Edinburgh: Sutherland \& Knox. London: Samuel Highley.

THE present work consists of an essay which was some years ago read before the Medico-Chirurgical Society of Edinburgh, and afterwards printed in the Transactions of the Society; but that work being no longer extant, the author has reproduced his essay before the profession in a separate form.

The subject is one which does not now claim so much the attention of medical men as it did when the author first penned these observations, for in the present day hospital gangrene is so rare, that it may almost with truth be said to be a disease of bygone days. Nevertheless it is occasionally met with even in civil practice; and as the surgeons of the British army may be again called upon to treat the same disorder upon a large scale, it behoves them to make themselves well acquainted with the experience of those who have gone before them.

The author was attached to the army in the Peninsula, and in his professional capacity was called upon to take charge of the extensive hospital at Bilbao, where a great number of wounded from the battle of Vittoria were collected together; there hospital gangrene was raging most furiously, consequently Dr. Boggie had ample scope for the investigation of this disease.

The main object of the work is to show the efficacy of the 